\title{
The carriers of the $\mathrm{A} / \mathrm{G}-\mathrm{G} / \mathrm{G}$ allelic combination of the c.2039 $A>G$ and c.-29 G>A FSH receptor polymorphisms retrieve the highest number of oocytes in IVF/ICSI cycles
}

\author{
Adolfo Allegra $^{1}$ - Angelo Marino ${ }^{1} \cdot$ Stefania Raimondo $^{2}$ - Antonio Maiorana ${ }^{3}$. \\ Salvatore Gullo $^{4} \cdot$ Piero Scaglione $^{1} \cdot$ Aldo Volpes $^{1} \cdot$ Riccardo Alessandro $^{2}$
}

Received: 26 July 2016 / Accepted: 23 October 2016/Published online: 5 November 2016

(C) Springer Science+Business Media New York 2016

\begin{abstract}
Purpose The objective of this study was the elucidation of the possible role of the single-nucleotide polymorphisms (SNP) at position -29 and 2039 of the FSH receptor gene (FSHR) as independent predictive markers of ovarian response. Indeed, the tailoring of reproductive treatments is crucial for both maximizing the success of IVF patients and obtaining a reduction in hypo- or hyper-response rates.

Methods This prospective, observational study analyzed the association of -29 and 2039 FSHR polymorphisms with the number of retrieved oocytes in 140 patients attending an IVF/ ICSI cycle for severe male factors $(\leq 5,000,000$ spermatozoa/ $\mathrm{mL}$ ) or tubal factors at the ANDROS Day Surgery Clinic, Palermo, Italy.

Results The results of this study demonstrate that the genetic combination of A/G for polymorphism c.2039 A>G with $\mathrm{G} / \mathrm{G}$ for polymorphism c.-29 G>A is significantly associated with the highest number of collected oocytes $(p=0.03)$. This association was significant even after controlling for the effect of other clinical variables.
\end{abstract}

Capsule The genetic variant $\mathrm{A} / \mathrm{G}-\mathrm{G} / \mathrm{G}$ is an independent predictor of the number of retrieved oocytes in IVF/ICSI cycles.

Adolfo Allegra

adolfo.allegra@clinicaandros.it

1 Reproductive Medicine Unit, ANDROS Day Surgery Clinic, Via Ausonia 43/45, 90144 Palermo, Italy

2 Dipartimento di Biopatologia e Biotecnologie Mediche, Università di Palermo, Palermo, Italy

3 Unità Operativa Complessa di Ginecologia ed Ostetricia, A.R.N.A.S. Ospedale Civico, Palermo, Italy

4 Medical Statistics Unit, ANDROS Day Surgery Clinic, Palermo, Italy
Conclusions The A/G-G/G allelic variant, identified as an independent variable, if confirmed in a larger number of patients, could be considered as a new genetic biomarker, which could increase the efficacy of prediction models for ovarian stimulation.

Keywords FSH receptor polymorphisms · Treatment personalization $\cdot \mathrm{COH} \cdot \mathrm{IVF} / \mathrm{ICSI}$

\section{Introduction}

The number of oocytes retrieved remains the key prognostic factor for pregnancy and live birth rates in patients undergoing assisted reproduction technologies (ART), and increasing evidence shows that an optimal oocyte yield is the main goal after controlled ovarian hyperstimulation $(\mathrm{COH})$ [1].

For these reasons, the tailoring of reproductive treatments is crucial for maximizing the success of IVF and simultaneously obtaining a reduction in hypo- or hyper-response rates. The biomarkers most widely used in clinical practice for predicting normal, poor, and high responders are female age, anti-Müllerian hormone (AMH), antral follicle count (AFC), and basal FSH (evaluated at the third day of the cycle). $\mathrm{AFC}$ and $\mathrm{AMH}$ are recognized as the most predictive factors for the ovarian response to gonadotropins. Nevertheless, these biomarkers alone do not allow an optimal personalization of IVF therapies for every patient, as it has been demonstrated that some patients can have a hyper-response when stimulated with a very low quantity of drugs and a hypo-response in cases of stimulation with high dosages of gonadotropins. Furthermore, there is also evidence that the "sensitivity" of follicles to exogenous FSH, measured through the Follicular Output RaTe (FORT), can vary among different patients with 
similar clinical characteristics; this seems in turn to be influenced by AMH levels with a negative correlation [2].

It can, therefore, be argued that genetic factors may play an important role in ovarian response to gonadotropins. The majority of the studies focused on the single-nucleotide polymorphisms (SNPs) of the FSH receptor gene (FSHR) and specifically on two substitutions of exon 10. The first SNP (rs6165) determines the nucleotide change (at position 919) of guanine with adenine (c.919 G>A) and the consequent amino acid substitution of threonine with alanine, at codon position 307 (p.Thr307Ala). The second SNP (rs6166) determines the nucleotide change (at position 2039) of adenine with guanine (c.2039 A>G), leading to the amino acid substitution of asparagine with serine at position 680 (p.Asn680Ser) [3]. These polymorphisms are in linkage disequilibrium. More recently, another polymorphism in the promoter region of the FSHR, in position -29, has been identified (rs1394205) [4]. This polymorphism is characterized by the substitution of guanine with adenine (GGAA in GAAA), and it seems to reduce the expression of $\bar{F} S H R$.

Different studies have analyzed the correlation between the FSHR polymorphisms, the ovarian reserve markers, and the outcome of the ovarian response to gonadotropins during IVF/ ICSI cycles. With regard to the association of the polymorphisms with ovarian reserve markers, the majority of the studies regard c.2039 A>G. In greater detail, the $\mathrm{G} / \mathrm{G}$ (Ser/Ser) variant has been associated with higher levels of basal FSH in some studies [5-11] but not in others [12-17]. Furthermore, in a review of 15 studies [18], an association of the $\mathrm{G} / \mathrm{G}$ variant with higher basal FSH levels was found in all of these studies except three of the studies included and quoted above [12-14].

The disagreement among studies regarding basal FSH levels can also be observed when analyzing the association of c.2039 A $>\mathrm{G}$ with ovarian response to gonadotropins. In the majority of the studies, the presence of $\mathrm{G} / \mathrm{G}$ was linked to a reduced sensitivity to exogenous FSH. This was demonstrated by a higher total dose of gonadotropins used during ovarian stimulation for IVF $[5,6,9,11]$, a lower peak of estradiol levels on the day of hCG administration [6, 19], a lower number of retrieved oocytes $[11,15]$, and a higher incidence of the $\mathrm{G} / \mathrm{G}$ variant in hypo-responder patients [20]. Furthermore, in a small study conducted with 37 patients, the A/A (Asn/Asn) variant was correlated to the severity of ovarian hyperstimulation syndrome (OHSS) [21]. In other studies, the association of the $\mathrm{G} / \mathrm{G}$ variant with a poor ovarian response was not demonstrated, either for the number of oocytes retrieved [22] or for the FORT [23]. Even those patients who were homozygous for the $\mathrm{G} / \mathrm{G}$ variant revealed a higher number of mature oocytes than the patients homozygous for the $\mathrm{A} / \mathrm{A}$ variant [10]. Regarding the effect of the c.2039 $\mathrm{A}>\mathrm{G}$ polymorphism on pregnancy, the conclusions of published studies [7, 13, 24] are highly conflicting. Indeed, in one study [7], the G/G variant was associated with a lower clinical pregnancy rate, whereas in the paper by Klinkert et al. [13], the A/A variant correlated to lower implantation and pregnancy rates than the $\mathrm{G} / \mathrm{G}$ variant. In the most recent study [24], the c.2039 A> G polymorphism was beneficial for pregnancy outcome only if combined with the luteinizing hormone/human chorionic gonadotropin receptor (LHCGR) variant Asn312Ser. Moreover, a recent meta-analysis failed to demonstrate a correlation between the $\mathrm{G} / \mathrm{G}$ variant and the clinical pregnancy rate [25]. Although the effect of the $\mathrm{G} / \mathrm{G}$ variant on a poor stimulation outcome was present in almost all the studies and confirmed by a meta-analysis [26] and by a recent review [27], clear clinical conclusions regarding the role of the c.2039 $A>G$ polymorphism as a predictive marker of ovarian stimulation have yet to be reached.

As regards the "new" FSHR polymorphism c.-29 G>A, few studies have been published [4, 28-31]. Specifically, Wunsch et al. [4] have found no correlation of this polymorphism with ovarian reserve or ovarian response to stimulation. The same conclusion was reached very recently by Tohlob et al. [28]. On the other hand, and with reference to the paper by Achrekar et al. [29], patients with the $\mathrm{A} / \mathrm{A}$ variant required a higher total dose of gonadotropins in order to reach significantly lower levels of estradiol on the day of hCG administration with a lower number of retrieved oocytes. The preliminary results of this study were subsequently confirmed with a demonstrated reduction in FSHR gene expression in granulosa cells [30]. By considering the association of the c.2039 $\mathrm{A}>\mathrm{G}$ and c. $-29 \mathrm{G}>\mathrm{A}$ polymorphisms, it has been proven that $75 \%$ of the patients with the combination A/A-A/A were poor responders, with a significant decrease in this category of FSHR expression in granulosa cells [31].

The objective of this prospective observational study was the analysis of the association between the FSHR polymorphisms c.2039 A>G and c.-29 G>A with the number of oocytes retrieved (primary outcome) in patients who underwent $\mathrm{COH}$ in IVF/ICSI cycles in order to elucidate their possible role as independent predictive markers of ovarian response.

\section{Materials and methods}

\section{Study subjects}

Analysis of the c.2039 A>G and c. $-29 \mathrm{G}>\mathrm{A}$ polymorphisms in FSHR was performed on 168 patients attending an IVF/ICSI cycle for severe male factors $(\leq 5,000,000$ spermatozoa/mL) or tubal factors at the ANDROS Day Surgery Clinic, Palermo, Italy. The c.919 G>A polymorphism was analyzed in all the patients but, on account of it being in complete linkage disequilibrium with c.2039 $\mathrm{A}>\mathrm{G}$, it was not included in the final analyses. 
The inclusion criteria were as follows:

- Female partners between 18 and 43 years of age

- BMI between 18 and $30 \mathrm{~kg} / \mathrm{m}^{2}$

- Normal regular menstrual cycles, ranging from 24 to 35 days in length, basal serum FSH $\leq 14 \mathrm{mIU} / \mathrm{mL}$, basal AMH level $\leq 4 \mathrm{ng} / \mathrm{mL}$, normal thyroid-stimulating hormone (TSH) and prolactin levels, and normal uterine cavity as assessed by hysteroscopy

Patients affected by polycystic ovary syndrome, severe endometriosis (stages III-IV of the ASRM revised classification) [32], or those who had previously undergone ovarian surgery or IVF/ICSI were excluded. On day 2 or 3 of the menstrual cycle, prior to commencing $\mathrm{COH}$, venous blood samples for analyzing FSHR polymorphisms and for the AMH, FSH, $\mathrm{TSH}$, and prolactin dosages were obtained from each patient. The AFC was performed on the same day using a Voluson ${ }^{\circledR}$ E8 BT12 (GE Healthcare, Italy), implemented with threedimensional ultrasound technology: Sonography-based Automatic Volume Calculation (SonoAVC). All the AFC determinations were performed by the same physician (AM), and all follicles measuring between 2 and $8 \mathrm{~mm}$ were included in the analysis.

The AMH dosage was effectuated using a Gen II ELISA (Beckman Coulter, Inc.) kit, an enzymatically amplified, two-site immunoassay by different laboratories. The lowest amount of AMH in a sample which could be detected with a $95 \%$ probability was $0.08 \mathrm{ng} / \mathrm{mL}$. $\mathrm{COH}$ was performed after pituitary down-regulation with a gonadotropin-releasing hormone agonist (GnRH-a, buserelin acetate; $0.1 \mathrm{~mL}$ twice per day) (Suprefact; Sanofi Aventis, Italy), beginning from day 21 of the previous cycle until the day of hCG administration. Multifollicular development was achieved by daily injections of recombinant human FSH (Gonal F; Merck Serono, Italy), commencing after at least 12 days of pituitary down-regulation. The choice of the stimulation protocol and starting dose of rhFSH was established independently by the presence of FSHR polymorphisms.

Treatment with a fixed dose of recombinant $\mathrm{FSH}$, based on female age, basal FSH, AMH, and AFC, was initiated for 5 days and then adjusted, according to the response of the ovaries to stimulation. Oocyte maturation was triggered with an injection of 10,000 IU of human chorionic gonadotropin (hCG, Gonasi HP; IBSA, Switzerland) when at least two follicles reached $17 \mathrm{~mm}$. The postponement of hCG trigger was not allowed in order to avoid the masking of the potential effect of FSHR polymorphisms on the ovarian response. Criteria for cycle cancellation before the day of hCG administration were either an inability to reach the
hCG criterion (less than two growing follicles) or more than 20 follicles with a diameter of $\geq 10 \mathrm{~mm}$. The oocyte pick-ups were performed $36 \mathrm{~h}$ after the triggering of oocyte maturation. IVF/ICSI were performed in accordance with the protocols described in Volpes et al. [33]. All embryo transfers were carried out using a Short Frydman set (Laboratoire CCD, Paris, France) between 48 and $120 \mathrm{~h}$ after oocyte pick-up. Micronized progesterone (Prometrium; Rottapharm S.p.A., Italy) was used for luteal support. Pregnancy was confirmed by determining serum $\beta$-hCG concentration 14 days after oocyte retrieval in all patients. When the pregnancy test resulted positive, a second test was performed 2 days later. Ultrasound evaluations were performed 28-32 days after oocyte pick-up, and only gestational sacs with a clear fetal heartbeat were diagnosed as clinical pregnancies.

This study was approved by the local Ethical Committee (the Ethical Committee of the ANDROS Day Surgery Clinic, Palermo, 04/MR/10).

\section{DNA isolation and genotyping analysis}

Six milliliters of whole blood was collected for each patient enrolled in the study, in two tubes with EDTA anticoagulant. Samples were stored at $4{ }^{\circ} \mathrm{C}$ before DNA isolation. Genomic DNA was extracted from peripheral blood leukocytes with a GenElute $^{\mathrm{TM}}$ Blood Genomic DNA Kit (Sigma-Aldrich, St. Louis, MO, USA), in accordance with the manufacturer's instructions. Genotyping analysis was performed using the Step-One Real-Time PCR (Applied Biosystems (ABI), Foster City, CA). Locus-specific PCR primers and allelespecific TaqMan probes (FSHR exon 10, rs6166, ID C_2676874_10; FSHR exon 10, rs6165, C_2676873_30; FSHR 5'UTR, rs1394205, ID C_426553_10) were supplied by Applied Biosystems. For each reaction, $10 \mu \mathrm{L}$ of TaqMan Genotyping Master Mix (2×), $1 \mu \mathrm{L}$ of SNP Genotyping Assay $(20 \times)$, and $10 \mathrm{ng}$ of genomic DNA were used. All the reactions consisted of one cycle at $95^{\circ} \mathrm{C}$ for $10 \mathrm{~min}, 40$ cycles at $95^{\circ} \mathrm{C}$ for $15 \mathrm{~s}$, and $60^{\circ} \mathrm{C}$ for $1 \mathrm{~min}$.

\section{Statistical analysis}

Values are presented as medians or means for continuous data and percentage (and frequencies) for categorical variables. Multivariate analyses, i.e., Student's $t$ test, ANOVA, or Wilcoxon signed-rank test, were performed to test differences among polymorphisms on female age, BMI, basal FSH, basal $17 \beta$-estradiol, AMH, AFC, rhFSH starting dose, days of rhFSH administration, total rhFSH units, the number of follicles $>16 \mathrm{~mm}$ on the hCG day, $17 \beta$-estradiol on the hCG day, and clinical pregnancy rate per embryo transfer. Pearson's $\chi^{2}$ 
test was used to test significant associations among categorical variables.

Chi-squared analysis for genotype distribution confirmed that both the polymorphisms were in Hardy-Weinberg equilibrium ( $p=0.23$ and $p=0.60$, for c.2039 $\mathrm{A}>\mathrm{G}$ and c. -29 $\mathrm{G}>\mathrm{A}$, respectively).

Poisson regression analysis in generalized linear models (GLM) was used to evaluate the effect of polymorphisms on the primary outcome, the number of retrieved oocytes. The Poisson regression model is a form of regression analysis specifically used to count data (integer-valued), and it is commonly applied in studies which screen for prognostic factors and which have many covariates. Poisson regression provides an indicator variable $(B)$, which is the expected difference in log count between each single group and the reference group. Due to the fact that a logarithmic scale is not easy to interpret, the regression coefficients have been exponentiated and presented as incident rate ratios (IRR). Poisson regression analyses were performed, with and without adjusting for confounders. The potential confounders included in the analyses were female age, BMI, basal FSH, basal $17 \beta$-estradiol, AMH, AFC, starting rhFSH dose, days of rhFSH administration, total rhFSH units, number of follicles $>16 \mathrm{~mm}$ on the hCG day (PFC), 17 $\beta$-estradiol on the hCG day, and FORT calculated as PFC (preovulatory follicle count) $\times 100 /$ AFC [2].

For the purpose of this study, a sample size calculation was made to determine the number of subjects that needed to be enrolled. With a power of $80 \%$ and an $\alpha$ of 0.05 , we determined that 140 subjects would be needed to at least replicate previous findings [31].

A two-sided $p$ value $<0.05$ was considered as statistically significant. Tests of model effects evaluated each of the model variables with appropriate degrees of freedom $(d f)$.

Given the low frequency of cases $(\leq 5), \mathrm{A} / \mathrm{A}$ genotype for c. $-29 \mathrm{G}>\mathrm{A}$ was excluded from the regression models and three out of the nine combinations of c.2039 $A>G$ and c.-29 G>A (A/A-A/A, A/G-A/A, and G/G-A/A) were excluded both from multivariate analyses and the regression models.

Thus, the genotypes were included in the regression analysis as categorical variables with three levels $(d f=$ 2) for c.2039 A $>\mathrm{G}$, two levels $(d f=1)$ for c. $-29 \mathrm{G}>\mathrm{A}$, and six levels $(d f=5)$ for the cross between the two genotypes. Analyses were processed with the statistical package PASW (SPSS Inc., Chicago, IL, version 18.0).

Nevertheless, in order to retain an important piece of information regarding the association of these genotypes with poor ovarian response, the total number of poor ovarian responders for each allelic variant and the odds ratio (OR) were calculated. The chi-squared test was used to study the significant association of the FSHR genotypes with poor ovarian response.

\section{Results}

\section{Frequency distribution of $F S H R$ polymorphisms in the study population and comparison with control group}

A total of 168 patients underwent the analysis of FSHR polymorphisms and started the IVF/ICSI cycle. Twenty-eight of the 168 patients $(16.7 \%)$ stopped the treatment for hyperresponse $(n=11)$ or hypo-response $(n=17)$. Therefore, 140 patients underwent oocyte retrievals and 123 underwent embryo transfer procedures, which means that $73 \%$ of patients who started the cycle ( $88 \%$ of those who underwent oocyte retrieval) ended up with an embryo transfer procedure. The total number of clinical pregnancies was 35 .

The suspended cycles were not distributed differently among the three c.2039 A>G, the three c. $-29 \mathrm{G}>\mathrm{A}$ genotypes, and their allelic combinations ( $p$ value ranged from 0.06 to $0.59)$.

The genotypic frequency for the c.2039 A $>$ G polymorphism in the sample being studied was $20 \%$ for the A/A genotype, $55 \%$ for the $\mathrm{A} / \mathrm{G}$ genotype, and $25 \%$ for the $\mathrm{G} / \mathrm{G}$ genotype. For the polymorphism at position c. $-29 \mathrm{G}>\mathrm{A}$, the frequency distribution was $62 \%$ for the GG genotype, $34 \%$ for the GA genotype, and $4 \%$ for the AA genotype. The frequency distribution of the FSHR polymorphisms in study subjects was compared with that in a control group of 87 subjects, which had been randomly selected from the general Caucasian female population (age ranged from 18 to 65 years), referred to the ANDROS Day Surgery Clinic, General Laboratory Unit, Palermo, Italy.

For the control group, the genotypic frequency for the polymorphism c.2039 A>G was $31 \%$ for the A/A genotype, $49 \%$ for the $\mathrm{A} / \mathrm{G}$ genotype, and $20 \%$ for the $\mathrm{G} / \mathrm{G}$ genotype. For the polymorphism at position c.-29 $\mathrm{G}>\mathrm{A}$, the frequency distribution was $57 \%$ for the $\mathrm{G} / \mathrm{G}$ genotype, $37 \%$ for the $\mathrm{G} / \mathrm{A}$ genotype, and $6 \%$ for the $\mathrm{A} / \mathrm{A}$ genotype. The frequencies of the different genotypic variants in study and control populations are reported in Table 1. The difference in frequency distributions between the control and study groups was not significant, either for c.2039 $\mathrm{A}>\mathrm{G}\left(\chi^{2}=3.17, d f=2, p=0.21\right)$ or c.$29 \mathrm{G}>\mathrm{A}\left(\chi^{2}=0.87, d f=2, p=0.65\right)$.

Although the study was conducted on a sufficient sample size as determined by the prior sample size analysis, the actual distribution of polymorphisms in the different groups was quite different from the expected one, producing a reduction in statistical power. As an alert regarding this point, we reported that 95\% CIs better interpreted non-significant results. 
Table 1 Frequencies of FSHR polymorphisms in the study population compared to the control group

\begin{tabular}{|c|c|c|c|c|}
\hline & \multicolumn{2}{|c|}{ Study group } & \multicolumn{2}{|c|}{ Control group } \\
\hline & $n$ & $\%$ & $n$ & $\%$ \\
\hline \multicolumn{5}{|c|}{ SNP c.2039 A>G } \\
\hline $\mathrm{A} / \mathrm{A}$ & 29 & 20.4 & 27 & 31.1 \\
\hline $\mathrm{A} / \mathrm{G}$ & 77 & 54.9 & 43 & 49.4 \\
\hline $\mathrm{G} / \mathrm{G}$ & 34 & 24.7 & 17 & 19.5 \\
\hline \multicolumn{5}{|c|}{ SNP c. $-29 \mathrm{G}>\mathrm{A}$} \\
\hline $\mathrm{G} / \mathrm{G}$ & 87 & 62.1 & 50 & 57.4 \\
\hline $\mathrm{G} / \mathrm{A}$ & 48 & 34.3 & 32 & 36.8 \\
\hline $\mathrm{A} / \mathrm{A}$ & 5 & 3.6 & 5 & 5.8 \\
\hline \multicolumn{5}{|c|}{ Combination SNPs c.2039 A>G and c. $-29 \mathrm{G}>\mathrm{A}$} \\
\hline A/A-G/G & 18 & 12.9 & 11 & 12.6 \\
\hline $\mathrm{A} / \mathrm{A}-\mathrm{G} / \mathrm{A}$ & 10 & 7.2 & 14 & 16.1 \\
\hline $\mathrm{A} / \mathrm{A}-\mathrm{A} / \mathrm{A}$ & 1 & 0.7 & 2 & 2.3 \\
\hline A/G-G/G & 44 & 31.4 & 26 & 30.0 \\
\hline A/G-G/A & 30 & 21.4 & 15 & 17.2 \\
\hline $\mathrm{A} / \mathrm{G}-\mathrm{A} / \mathrm{A}$ & 3 & 2.1 & 2 & 2.3 \\
\hline $\mathrm{G} / \mathrm{G}-\mathrm{G} / \mathrm{G}$ & 25 & 17.9 & 13 & 15.0 \\
\hline G/G-G/A & 8 & 5.7 & 3 & 3.4 \\
\hline G/G-A/A & 1 & 0.7 & 1 & 1.1 \\
\hline
\end{tabular}

\section{Analysis of the association between the FSHR polymorphisms and the clinical variables}

An analysis of differences of study variables among the three c.2039 $\mathrm{A}>\mathrm{G}$ and the three c.-29 $\mathrm{G}>\mathrm{A}$ genotypes is shown in Table 2; an analysis of differences of study variables among the retained combinations of the two polymorphisms is shown in Table 3.

The results from the ANOVA revealed that basal $17 \beta-$ estradiol for $\mathrm{c} .2039 \mathrm{~A}>\mathrm{G}$ was significantly higher in $\mathrm{A} / \mathrm{A}$ than in $\mathrm{A} / \mathrm{G}(p<0.05)$, whereas for c. $29 \mathrm{G}>\mathrm{A}$, the $\mathrm{A} / \mathrm{A}$ variant displayed a lower AFC than the wild type $(p<0.05)$; no other significant differences among the study variables were identified (Table 2). In Table 3, the allelic combinations of c.2039 $\mathrm{A}>\mathrm{G}$ and $-29 \mathrm{G}>\mathrm{A}$ were associated with basal FSH, basal $17 \beta$-estradiol, AFC, and FORT. In detail, comparisons revealed that the $A / G-G / G$ genetic variant had lower levels of basal FSH and basal $17 \beta$-estradiol than the $\mathrm{A} / \mathrm{A}-\mathrm{G} / \mathrm{A}$ and $\mathrm{G} / \mathrm{G}-\mathrm{G} / \mathrm{G}$ variants $(p<0.05)$, a higher $\mathrm{AFC}$ in comparison with $\mathrm{A} / \mathrm{G}-\mathrm{G} / \mathrm{A}$ and $\mathrm{G} / \mathrm{G}-\mathrm{G} / \mathrm{G}$ variants $(p<0.05)$, and lower FORT in comparison with $\mathrm{A} / \mathrm{A}-\mathrm{G} / \mathrm{A}$ and $\mathrm{G} / \mathrm{G}-\mathrm{G} / \mathrm{A}$ variants $(p<0.05)$.

The starting dose of rhFSH is not significantly different between c.2039 A>G, c.-29 G>A and their combinations ( $p$ value ranged from 0.84 to 0.92 ) (Tables 2 and 3 ). In a

Table 2 Differences in study variables for the different variants of FSHR polymorphisms c.2039 A >G and c.-29 G>A

\begin{tabular}{|c|c|c|c|c|c|c|c|c|}
\hline & \multicolumn{4}{|l|}{ c. $2039 \mathrm{~A}>\mathrm{G}$} & \multicolumn{3}{|l|}{ c. $-29 \mathrm{G}>\mathrm{A}$} & \multirow[b]{2}{*}{$p$} \\
\hline & $\mathrm{A} / \mathrm{A}$ & $\mathrm{A} / \mathrm{G}$ & $\mathrm{G} / \mathrm{G}$ & $p$ & $\mathrm{G} / \mathrm{G}$ & $\mathrm{G} / \mathrm{A}$ & $\mathrm{A} / \mathrm{A}$ & \\
\hline $\mathrm{Age}^{1}$ & $32.0(21-40)$ & $33.0(21-42)$ & $32.5(21-40)$ & 0.46 & $33.0(21-42)$ & $33.0(22-41)$ & $30.0(26-35)$ & 0.30 \\
\hline BMI $\left(\mathrm{kg} / \mathrm{m}^{2}\right)^{1}$ & $22.7(17.8-29.1)$ & $22.7(17.8-29.8)$ & $22.0(18.9-29.9)$ & 0.38 & $22.0(17.6-29.8)$ & $22.5(17.8-29.0)$ & $23.0(21.0-29.0)$ & 0.60 \\
\hline Basal FSH (IU/L) ${ }^{1}$ & $6.56(3.7-13.8)$ & $6.29(3.3-13.1)$ & $7.37(4.8-13.1)$ & 0.06 & $6.5(3.3-13.1)$ & $7.1(4.0-13.1)$ & $7.2(5.8-8.0)$ & 0.26 \\
\hline Basal $17 \beta$ E2 $(\mathrm{pg} / \mathrm{mL})^{1}$ & $59.4^{\mathrm{a}}(10-232)$ & $40.0^{\mathrm{b}}(9-104)$ & $50.0^{\mathrm{ab}}(18-99)$ & 0.02 & $44.0(9-232)$ & $49.0(13-104)$ & $67.0(48-99)$ & 0.06 \\
\hline $\mathrm{AMH}(\mathrm{ng} / \mathrm{mL})^{1}$ & $1.4(0.2-3.5)$ & $1.7(0.3-3.5)$ & $2.2(0.1-3.1)$ & 0.49 & $1.8(0.4-3.2)$ & $1.6(0.1-3.5)$ & $0.2(0.2-0.3)$ & 0.06 \\
\hline Antral follicle count ${ }^{1}$ & $9.0(3-18)$ & $10.0(3-46)$ & $8.0(8-25)$ & 0.44 & $10.0^{\mathrm{b}}(1-46)$ & $8.0^{\mathrm{ab}}(2-25)$ & $6.0^{\mathrm{a}}(4-14)$ & 0.04 \\
\hline $\begin{array}{l}\text { Starting dose of } \\
\text { rhFSH (IU) }{ }^{1}\end{array}$ & $150(75-300)$ & $150(75-450)$ & $150(75-450)$ & 0.92 & $150.0(75-450)$ & $150.0(75-450)$ & $150.0(75-150)$ & 0.89 \\
\hline $\begin{array}{l}\text { Days of rhFSH } \\
\text { treatment }^{1}\end{array}$ & $12(7-17)$ & $11.5(6-19)$ & $12(7-15)$ & 0.80 & $12(7-17)$ & $12(6-19)$ & $15(10-17)$ & 0.13 \\
\hline $\begin{array}{l}\text { Total dose of rhFSH } \\
\text { (IU) }{ }^{1}\end{array}$ & $\begin{array}{l}1687.5 \\
\quad(900-4050)\end{array}$ & $\begin{array}{l}1875.0 \\
\quad(863-6300)\end{array}$ & $\begin{array}{l}1954.0 \\
\quad(675-4125)\end{array}$ & 0.60 & $\begin{array}{l}1800.0 \\
\quad(675-4125)\end{array}$ & $\begin{array}{l}1800.0 \\
\quad(850-6300)\end{array}$ & $\begin{array}{l}3000.0 \\
\quad(1800-3825)\end{array}$ & 0.17 \\
\hline $\begin{array}{l}17 \beta \text { E2 on the hCG } \\
\text { day }(\mathrm{pg} / \mathrm{mL})^{1}\end{array}$ & $\begin{array}{l}1274.0 \\
(304-2352)\end{array}$ & $\begin{array}{l}1390.0 \\
\quad(210-3965)\end{array}$ & $\begin{array}{l}1479.0 \\
\quad(329-3507)\end{array}$ & 0.68 & $\begin{array}{l}1384.0 \\
\quad(304-3965)\end{array}$ & $\begin{array}{l}1314.0 \\
\quad(210-2600)\end{array}$ & $\begin{array}{l}1388.0 \\
\quad(631-1954)\end{array}$ & 0.91 \\
\hline $\begin{array}{l}\text { Number of follicles }> \\
16 \mathrm{~mm} \text { on the hCG } \\
\text { day }^{1}\end{array}$ & $6.0(2-13)$ & $6.5(1-13)$ & $7.0(3-10)$ & 0.39 & $6.0(2-11)$ & $7.0(1-13)$ & $6.0(5-8)$ & 0.65 \\
\hline FORT $^{2}$ & $69 \%$ & $63 \%$ & $76 \%$ & 0.09 & $63 \%$ & $73 \%$ & $79 \%$ & 0.07 \\
\hline Retrieved oocytes $^{3}$ & $7.17( \pm 2.4)$ & $8.12( \pm 2.2)$ & $6.74( \pm 2.4)$ & 0.54 & $8.2( \pm 4.7)$ & $6.7( \pm 3.5)$ & $6.2( \pm 4.1)$ & 0.84 \\
\hline $\begin{array}{l}\text { Clinical pregnancy per } \\
\mathrm{ET}^{4}\end{array}$ & $7 / 27(26 \%)$ & $20 / 68(30 \%)$ & $8 / 28(29 \%)$ & 0.94 & $21 / 76(28 \%)$ & $12 / 43(28 \%)$ & $2 / 4(50 \%)$ & 0.64 \\
\hline
\end{tabular}

Differences among figures with common superscript letters are not significant

${ }^{1}$ Values are expressed in median and range in brackets. ${ }^{2}$ FORT is expressed in percentage. ${ }^{3}$ Retrieved oocytes are expressed in mean and standard deviation in brackets. ${ }^{4}$ Pregnancies per embryo transfer are expressed in number and percentage 
Table 3 Differences of the study variables for the cross c.2039 A $>$ G $\times$ c. -29 G $>$ A

\begin{tabular}{|c|c|c|c|c|c|c|c|}
\hline & \multicolumn{6}{|c|}{ c. $2039 \mathrm{~A}>\mathrm{G} \times$ c. $-29 \mathrm{G}>\mathrm{A}$} & \multirow[b]{2}{*}{$p$} \\
\hline & A/A-G/A & $\mathrm{A} / \mathrm{A}-\mathrm{G} / \mathrm{G}$ & A/G-G/A & A/G-G/G & G/G-G/A & $\mathrm{G} / \mathrm{G}-\mathrm{G} / \mathrm{G}$ & \\
\hline $\mathrm{Age}^{1}$ & $31.0(25-36)$ & $33.0(21-40)$ & $34.0(22-41)$ & $33.0(21-42)$ & $31.0(22-36)$ & $33.0(21-40)$ & 0.58 \\
\hline BMI $\left(\mathrm{kg} / \mathrm{m}^{2}\right)^{1}$ & $23.2(18.8-27.3)$ & $21.6(17.6-29.1)$ & $22.5(17.8-29.0)$ & $22.7(18.7-29.8)$ & $20.8(19.5-27.2)$ & $22.0(18.9-29.9)$ & 0.81 \\
\hline Basal FSH $(\mathrm{IU} / \mathrm{L})^{1}$ & $7.9^{\mathrm{a}}(5.8-8.0)$ & $6.3^{\mathrm{ab}}(3.7-13.2)$ & $7.0^{\mathrm{ab}}(4.0-13.1)$ & $5.9^{\mathrm{b}}(3.3-12.7)$ & $7.2^{\mathrm{ab}}(5.5-12.7)$ & $7.7^{\mathrm{a}}(4.8-13.1)$ & 0.04 \\
\hline Basal $17 \beta$ E2 $(\mathrm{pg} / \mathrm{mL})^{1}$ & $60.8^{\mathrm{a}}(46-96)$ & $46.0^{\mathrm{ab}}(10-232)$ & $43.0^{\mathrm{ab}}(13-104)$ & $35.0^{\mathrm{b}}(9-94)$ & $45.5^{\mathrm{ab}}(18-67)$ & $49.0^{\mathrm{a}}(23-94)$ & 0.03 \\
\hline $\mathrm{AMH}(\mathrm{ng} / \mathrm{mL})^{1}$ & $1.9(0.2-3.2)$ & $1.3(0.5-3.5)$ & $1.4(0.4-3.5)$ & $2.1(0.6-3.2)$ & $2.5(0.1-3.1)$ & $2.1(0.4-3.1)$ & 0.25 \\
\hline Antral follicle count ${ }^{1}$ & $9.0^{\mathrm{ab}}(4-14)$ & $8.5^{\mathrm{ab}}(3-18)$ & $7.0^{\mathrm{a}}(3-17)$ & $12.0^{\mathrm{b}}(4-46)$ & $10.0^{\mathrm{ab}}(2-25)$ & $8.0^{\mathrm{a}}(1-25)$ & 0.04 \\
\hline $\begin{array}{l}\text { Starting dose of rhFSH } \\
(\text { (IU) })^{1}\end{array}$ & $150.0(75-300)$ & $150.0(75-300)$ & $150.0(75-300)$ & $150.0(75-450)$ & $93.8(75-300)$ & $150.0(75-450)$ & 0.84 \\
\hline Days of rhFSH treatment ${ }^{1}$ & $12(10-14)$ & $12(7-15)$ & $12(6-19)$ & $11(7-17)$ & $12(7-14)$ & $12(8-17)$ & 0.78 \\
\hline Total dose of rhFSH (IU) ${ }^{1}$ & $\begin{array}{l}1800.0 \\
\quad(900-3150)\end{array}$ & $\begin{array}{l}1668.8 \\
\quad(1013-4050)\end{array}$ & $\begin{array}{l}1875.0 \\
\quad(975-6300)\end{array}$ & $\begin{array}{l}1762.5 \\
\quad(863-3900)\end{array}$ & $\begin{array}{l}1500.0 \\
\quad(850-3300)\end{array}$ & $\begin{array}{l}2025.0 \\
\quad(675-4125)\end{array}$ & 0.62 \\
\hline $\begin{array}{l}17 \beta \text { E2 on the } \mathrm{hCG} \\
\text { day }(\mathrm{pg} / \mathrm{mL})^{1}\end{array}$ & $\begin{array}{l}1211.0 \\
(589-1989)\end{array}$ & $\begin{array}{l}1306.5 \\
\quad(304-2352)\end{array}$ & $\begin{array}{l}1184.0 \\
\quad(210-2600)\end{array}$ & $\begin{array}{l}1423.5 \\
\quad(569-3965)\end{array}$ & $\begin{array}{l}1544.0 \\
\quad(850-2470)\end{array}$ & $\begin{array}{l}1352.0 \\
\quad(329-3507)\end{array}$ & 0.83 \\
\hline $\begin{array}{l}\text { Number of follicles }>16 \\
\text { mm on the hCG day }\end{array}$ & $7.0(4-13)$ & $6.0(2-11)$ & $6.0(1-13)$ & $7.0(2-11)$ & $8.0(4-10)$ & $6.0(3-9)$ & 0.79 \\
\hline FORT $^{2}$ & $80 \%^{\mathrm{a}}$ & $66 \%{ }^{\mathrm{ab}}$ & $71 \%{ }^{\mathrm{ab}}$ & $56 \%{ }^{\mathrm{b}}$ & $79 \%^{\mathrm{a}}$ & $74 \%{ }^{\mathrm{ab}}$ & 0.04 \\
\hline Retrieved oocytes $^{3}$ & $7.0(2.5)^{\mathrm{a}}$ & $7.5(3.2)^{\mathrm{ab}}$ & $6.7(3.7)^{\mathrm{ab}}$ & $9.3(4.6)^{\mathrm{b}}$ & $6.1(3.8)^{\mathrm{ab}}$ & $6.7(3.1)^{\mathrm{ab}}$ & 0.03 \\
\hline $\begin{array}{l}\text { Clinical pregnancy per } \\
\mathrm{ET}^{4}\end{array}$ & $3 / 9(33 \%)$ & $4 / 17(24 \%)$ & $8 / 27(30 \%)$ & $10 / 39(26 \%)$ & $1 / 7(14 \%)$ & $7 / 20(35 \%)$ & 0.49 \\
\hline
\end{tabular}

Differences among figures with common superscript letters are not significant

${ }^{1}$ Values are expressed in median and range in brackets. ${ }^{2}$ FORT is expressed in percentage. ${ }^{3}$ Retrieved oocytes are expressed in mean and standard deviation in brackets. ${ }^{4}$ Pregnancies per embryo transfer are expressed in number and percentage

similar way, no differences were found for the days of rhFSH administration ( $p$ value ranged from 0.13 to 0.84 ) nor for the total dose of rhFSH ( $p$ value ranged from 0.17 to 0.62 ) (Tables 2 and 3). The percentage of patients for whom the dose of rhFSH was adjusted during ovarian stimulation was not significantly different between the three c.2039 A > G and the three $-29 \mathrm{G}>\mathrm{A}$ genotypes as well as for their six allelic combinations.

\section{Analysis of the association between the FSHR polymorphisms and the number of oocytes retrieved}

Initially, we performed Poisson regression analysis without covariates to verify the predictive effect of the polymorphisms on the number of retrieved oocytes. Results showed that both c. $2039 \mathrm{~A}>\mathrm{G}$ (Wald $\chi^{2}=3.65, d f=2, p=0.16$ ) and c. $-29 \mathrm{G}>\mathrm{A}$ (Wald $\chi^{2}=5.29, d f=2, p=0.07$ ) did not significantly predict the outcome, whereas the c.2039 A>G/c.-29 G>A cross was a significant predictor (Wald $\chi^{2}=12.66, d f=5, p=0.03$ ). Table 4 shows the effect (relative change) of each variant in outcome; the relative change is obtained by comparing the variants with the reference group (A/A-G/G, the double wild type). We found a single significant effect, i.e., an increase in 0.21 ( $p=0.03$, IRR 1.24) in A/G-G/G compared with A/A-G/ $\mathrm{G}$; it can be stated that the incident rate for $\mathrm{A} / \mathrm{G}-\mathrm{G} / \mathrm{G}$ is 1.24 times the incident rate for the reference group (Fig. 1). The other variants showed a slight but non-significant decrease compared with the reference group. The mean number of retrieved oocytes was $9.30( \pm 4.6)$ for $\mathrm{A} / \mathrm{G}-\mathrm{G} / \mathrm{G}$ and $7.50( \pm 3.2)$ for $\mathrm{A} / \mathrm{A}-\mathrm{G} / \mathrm{G}$; the median, quartiles, and minimum and maximum for each variant are shown in Fig. 2.

Verifying the predictive effect of polymorphisms by taking into account the effect of covariates (confounding variables), the subsequent Poisson regression analysis confirmed that c.2039 A $>\mathrm{G}$ was not a statistically significant predictor of the number of retrieved oocytes (Wald $\chi^{2}=2.21, d f=2$,

Table 4 Poisson regression for the c.2039 A>G $\times$ c. -29 G $>$ A cross

\begin{tabular}{|c|c|c|c|c|c|c|c|c|}
\hline & \multirow[t]{2}{*}{$B$} & \multirow[t]{2}{*}{$\mathrm{SE}$} & \multirow[b]{2}{*}{$\mathrm{W}-\chi^{2}$} & \multirow[b]{2}{*}{$d f$} & \multirow[b]{2}{*}{$p$} & \multirow[t]{2}{*}{ IRR } & \multicolumn{2}{|c|}{$95 \% \mathrm{~W}-\mathrm{CI}$} \\
\hline & & & & & & & Lower & Upper \\
\hline $\mathrm{A} / \mathrm{A}-\mathrm{G} / \mathrm{A}$ & -0.06 & 0.14 & 0.21 & 1 & 0.64 & 0.93 & 0.6 & 1.26 \\
\hline $\mathrm{A} / \mathrm{G}-\mathrm{G} / \mathrm{A}$ & -0.11 & 0.11 & 1.02 & 1 & 0.31 & 0.89 & 0.71 & 1.11 \\
\hline $\mathrm{A} / \mathrm{G}-\mathrm{G} / \mathrm{G}$ & 0.21 & 0.09 & 4.67 & 1 & 0.03 & 1.24 & 1.02 & 1.50 \\
\hline G/G-G/A & -0.20 & 0.16 & 1.47 & 1 & 0.22 & 0.81 & 0.58 & 1.13 \\
\hline G/G-G/G & -0.11 & 0.11 & 1.00 & 1 & 0.31 & 0.89 & 0.71 & 1.11 \\
\hline A/A-G/G & 0 & - & - & - & - & 1 & - & - \\
\hline
\end{tabular}

$B$ expected difference in log count, $S E$ standard error, $W-\chi^{2}$ Wald $\chi^{2}$ test for hypothesis, $d f$ degrees of freedom, $p$ level of significance, IRR incidence rate ratio, $W$-CI Wald confidence interval for IRR, A/A-G/G reference group 


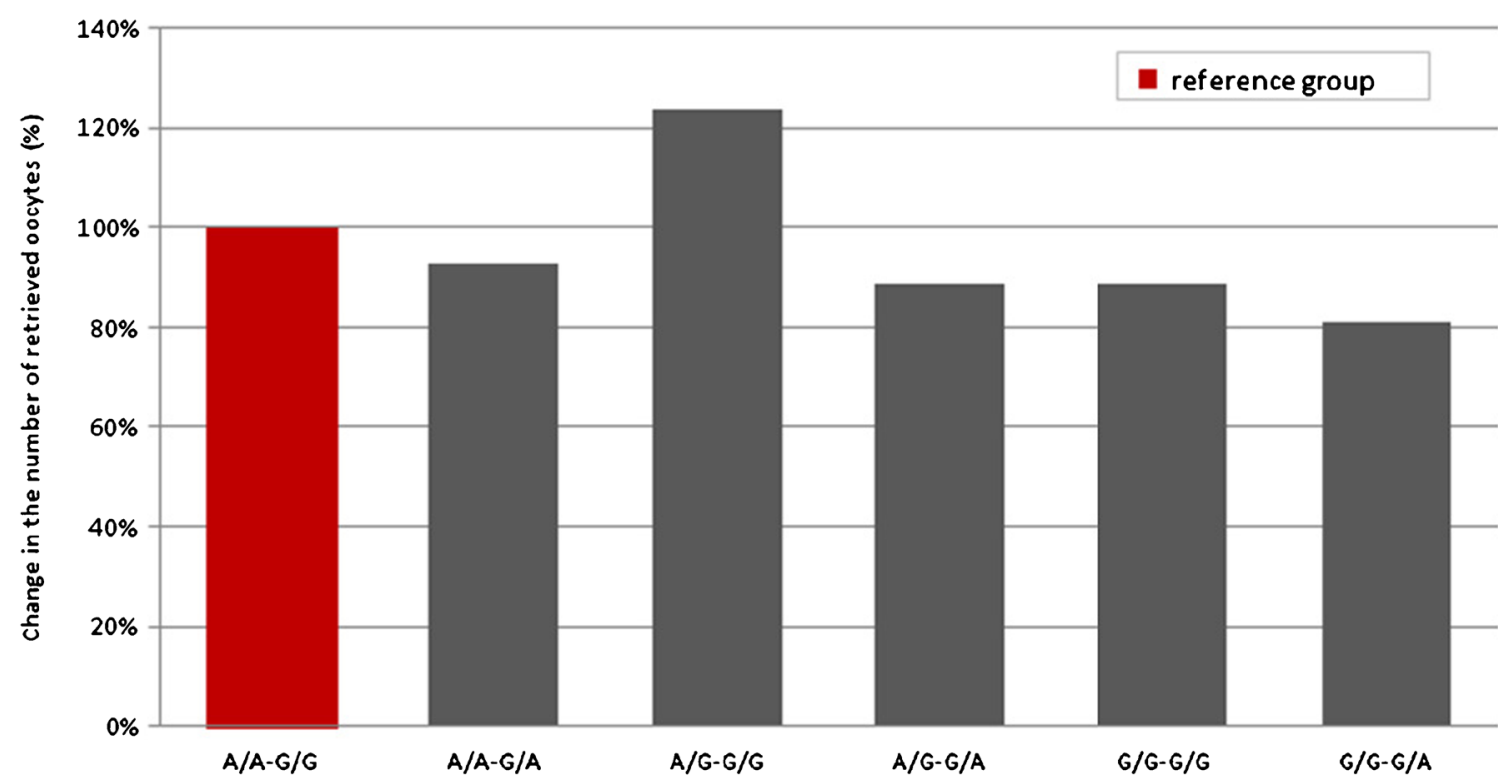

Fig. 1 Relative change in the number of retrieved oocytes for each genetic variant compared to the reference group

$p=0.33)$. Specifically, the outcome was not significantly different either regarding the $\mathrm{A} / \mathrm{A}$ or $\mathrm{A} / \mathrm{G}$ variant compared with $\mathrm{G} / \mathrm{G}(p=0.44, \mathrm{IRR}=1.10$ and $p=0.14, \mathrm{IRR}=1.16$, respectively). Among the covariates, AFC was positively associated with the outcome $(p=0.04)$, whereas BMI and starting dose were negatively associated $(p=0.04)$.

Similarly, the Poisson regression analysis for c. $-29 \mathrm{G}>\mathrm{A}$ demonstrated that this polymorphism was not a statistically significant predictor of the number of retrieved oocytes (Wald $\chi^{2}=2.29, d f=1, p=0.13$ ). The number of retrieved oocytes for the $\mathrm{G} / \mathrm{A}$ variant was not different from the $\mathrm{G} / \mathrm{G}$ variant $(p=0.08, I R R=3.17)$. Among the confounding variables, AFC was positively associated with outcome $(p=$ 0.03 ), whereas BMI and starting dose were negatively associated $(p=0.04)$. When considering the six variants obtained by crossing the two polymorphisms, we found that the model remained statistically significant (Wald $\chi^{2}=13.22, d f=5$, $p=0.02$ ). Compared with the reference group, the increase for $\mathrm{A} / \mathrm{G}-\mathrm{G} / \mathrm{G}$ remained the only significant effect also after the inclusion of the covariates $(p=0.04, \operatorname{IRR}=1.18)$. In this case too, the covariates (BMI, AFC, and starting dose) influenced the outcome in the same aforementioned manner.

Finally, since the allelic combinations with small numbers were not considered for comparison during regression
Fig. 2 Boxplot of medians, quartiles, and minimum and maximum of retrieved oocytes for the c.2039 A>G × c. $-29 \mathrm{G}>\mathrm{A}$ cross

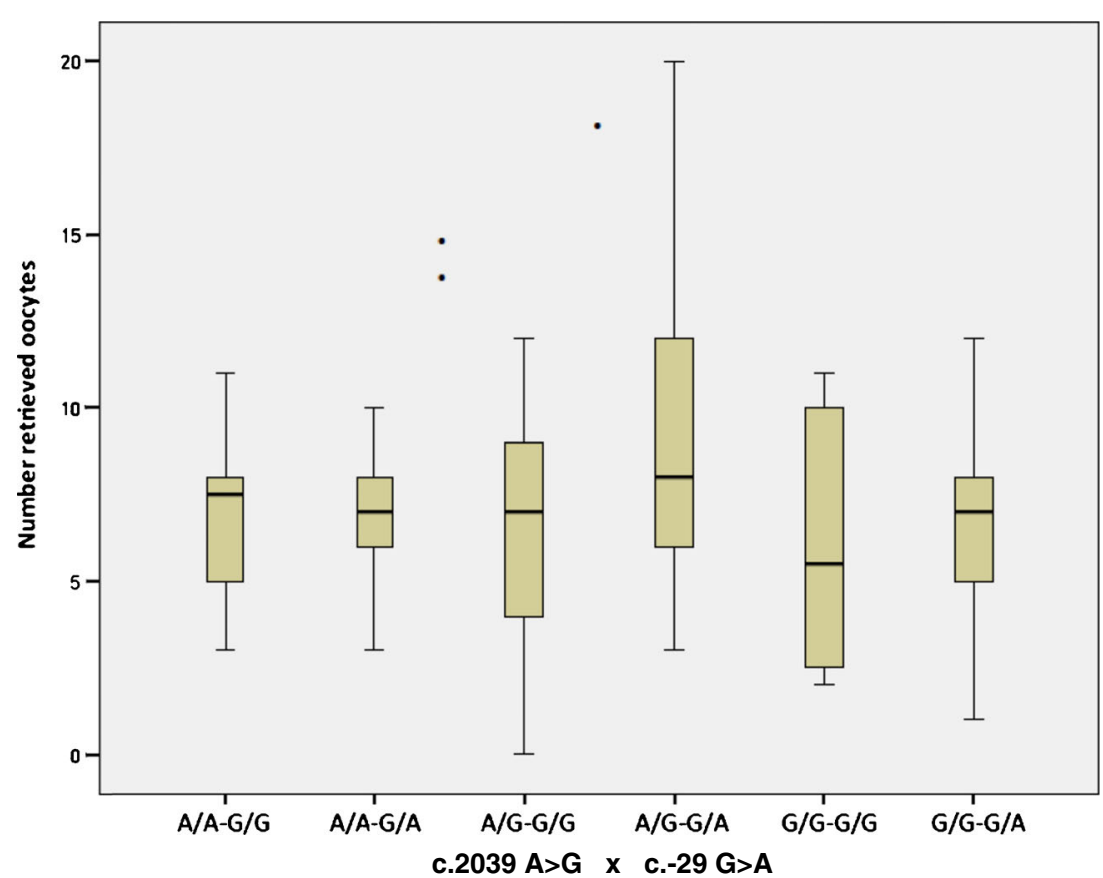


Table 5 Odds ratio for c.2039 A $>$ G, c. $-29 \mathrm{G}>\mathrm{A}$, and their allelic combination

\begin{tabular}{|c|c|c|c|c|c|c|}
\hline & \multirow{2}{*}{$\begin{array}{l}\text { Poor response }(<5) \\
n\end{array}$} & \multirow{2}{*}{$\begin{array}{l}\text { Normal response }(\geq 5) \\
n\end{array}$} & \multirow[t]{2}{*}{ OR } & \multirow[t]{2}{*}{$p$ value } & \multicolumn{2}{|l|}{$95 \% \mathrm{CI}$} \\
\hline & & & & & Lower & Upper \\
\hline \multicolumn{7}{|c|}{ SNP c.2039 A>G } \\
\hline $\mathrm{A} / \mathrm{A}$ & 5 & 24 & 0.76 & 0.60 & 0.26 & 2.19 \\
\hline $\mathrm{A} / \mathrm{G}$ & 14 & 63 & 0.44 & 0.04 & 0.21 & 0.95 \\
\hline $\mathrm{G} / \mathrm{G}$ & 10 & 24 & 1.91 & 0.15 & 0.78 & 4.64 \\
\hline \multicolumn{7}{|c|}{ SNP c.-29 G>A } \\
\hline $\mathrm{G} / \mathrm{G}$ & 12 & 75 & 0.34 & 0.01 & 0.15 & 0.78 \\
\hline $\mathrm{G} / \mathrm{A}$ & 14 & 34 & 2.11 & 0.08 & 0.92 & 4.86 \\
\hline $\mathrm{A} / \mathrm{A}$ & 3 & 2 & 6.23 & 0.05 & 0.99 & 39.58 \\
\hline \multicolumn{7}{|c|}{ Combination SNPs c.2039 A $>$ G and c. $-29 \mathrm{G}>\mathrm{A}$} \\
\hline A/A-G/G & 2 & 16 & 0.48 & 0.36 & 0.10 & 2.25 \\
\hline $\mathrm{A} / \mathrm{A}-\mathrm{G} / \mathrm{A}$ & 2 & 8 & 1.05 & 0.95 & 0.21 & 5.27 \\
\hline $\mathrm{A} / \mathrm{A}-\mathrm{A} / \mathrm{A}$ & 1 & 0 & 11.74 & 0.13 & 0.47 & 295.81 \\
\hline $\mathrm{A} / \mathrm{G}-\mathrm{G} / \mathrm{G}$ & 4 & 40 & 0.31 & 0.04 & 0.10 & 0.96 \\
\hline $\mathrm{A} / \mathrm{G}-\mathrm{G} / \mathrm{A}$ & 8 & 22 & 1.76 & 0.25 & 0.68 & 4.57 \\
\hline $\mathrm{A} / \mathrm{G}-\mathrm{A} / \mathrm{A}$ & 2 & 1 & 8.15 & 0.09 & 0.72 & 93.21 \\
\hline $\mathrm{G} / \mathrm{G}-\mathrm{G} / \mathrm{G}$ & 6 & 19 & 1.42 & 0.66 & 0.50 & 4.01 \\
\hline G/G-G/A & 4 & 4 & 0.48 & 0.20 & 0.15 & 1.47 \\
\hline $\mathrm{G} / \mathrm{G}-\mathrm{A} / \mathrm{A}$ & 0 & 1 & 1.25 & 0.89 & 0.04 & 31.45 \\
\hline
\end{tabular}

$O R$ odds ratio, $C I$ confidence interval for $\mathrm{OR}$ analysis, an additional analysis was carried out by calculating the total number of poor ovarian responders for each allelic variant and the relative OR. Twenty-nine (21\%) out of the 140 study subjects had less than 5 retrieved oocytes and were classified as poor ovarian responders.

Table 5 shows the distribution of poor versus normal responders segregated by genotype; it was observed that the number of poor ovarian responders ranged from 17 to $29 \%$ for c.2039 A $>\mathrm{G}$ and from 14 to $60 \%$ for c. $-29 \mathrm{G}>\mathrm{A}$. The chisquared test was employed to study the significant association of the FSHR genotypes with poor ovarian response. The poor response rate was lower in $\mathrm{A} / \mathrm{G}$ for c.2039 $\mathrm{A}>\mathrm{G}$ genotype (OR $0.44,95 \%$ CI $0.21-0.95 ; p=0.04$ ) and in $\mathrm{G} / \mathrm{G}$ for c. $-29 \mathrm{G}>\mathrm{A}$ genotype (OR 0.34, 95\% CI 0.15-0.78; $p=0.01$ ). By considering the allelic combinations of the two polymorphisms, a lower poor response rate was confirmed for the A/G-G/G variant. The OR for the other genotypes and allelic combinations was not significant (Table 5).

\section{Discussion}

This study analyzed the association of the FSHR c.2039 A>G and c. $-29 \mathrm{G}>\mathrm{A}$ polymorphisms with the ovarian response to FSH stimulation during IVF/ICSI cycles in a Caucasian population. The main results of this paper demonstrate that the A/G-G/G genetic combination of the two polymorphisms is associated significantly with the highest number of collected oocytes, in comparison with the other genetic variants. This association was significant even after controlling for the effect of the other clinical confounding variables. Furthermore, the carriers of the $\mathrm{A} / \mathrm{G}-\mathrm{G} / \mathrm{G}$ variant showed a lower poor response rate. The same finding (a lower poor response rate) was observed when also considering the variants $\mathrm{A} / \mathrm{G}$ for c.2039 $\mathrm{A}>\mathrm{G}$ and $\mathrm{G} / \mathrm{G}$ for c.-29 $\mathrm{G}>\mathrm{A}$ alone.

As far as we know, only three studies have analyzed the association of c.2039 A>G and c.-29 G>A [4, 28, 31]. In the study by Wunsch et al. [4], the authors considered the peak estradiol levels as an outcome measure of ovarian response, and they did not identify any correlation with the single polymorphism and their combination. The second study [28] showed that patients carrying the diplotype with variant alleles for both the polymorphisms ( $\mathrm{G}$ for c.2039 A $>\mathrm{G}$ and A for c.$29 \mathrm{G}>\mathrm{A}$ ) were more likely to have a hyper-response to stimulation but, again, no correlation was observed with poor response. Considering the third study [30], conducted on an Indian population, the authors found that A/A (Asn/Asn)-G/ $\mathrm{G}$ and $\mathrm{A} / \mathrm{G}$ (Asn/Ser)-G/G were the genetic combinations associated with the highest number of collected oocytes. Specifically, the difference between these two categories was not significant ( $16.4 \pm 1.5$ vs. $15.1 \pm 1.2)$. Similarly, A/A-G/G and $\mathrm{A} / \mathrm{G}-\mathrm{G} / \mathrm{G}$ were associated in our study with the highest number of collected oocytes with no significant difference between them ( $7.5 \pm 3.2$ vs. $9.3 \pm 4.6)$, although our best combination, A/G-G/G, differs from that of Desay et al. [31], A/A$\mathrm{G} / \mathrm{G}$. The congruence of the results, while not complete, leads 
the authors of this paper to emphasize the major role of the $\mathrm{G} / \mathrm{G}$ variant of c.-29 $\mathrm{G}>\mathrm{A}$ in determining a positive ovarian response.

Moreover, A/G-G/G was associated with higher AFC, lower basal FSH, lower $17 \beta$-estradiol and lower FORT in comparison with other genetic variants, supporting its positive predictive factor for the success of ovarian stimulation. The positive association between $\mathrm{A} / \mathrm{G}-\mathrm{G} / \mathrm{G}$ and basal FSH contradicts the published studies which considered the different allelic combinations of c.2039 $\mathrm{A}>\mathrm{G}$ and c.-29 $\mathrm{G}>\mathrm{A}[4,28,31]$, where no correlation with basal FSH was found. The negative association with FORT could be explained by the selection of the antral follicles with the greatest developmental potential.

Our data concerning the c.2039 A>G polymorphism is in line with that described by Mohiyiddeen et al. [22] in which the association of the $\mathrm{G} / \mathrm{G}$ variant with a poor outcome was not demonstrated. As previously described, there is marked disagreement in literature analyzing the association of c.2039 $\mathrm{A}>\mathrm{G}$ with the ovarian response to gonadotropins. In the majority of the studies, the presence of the $\mathrm{G} / \mathrm{G}$ variant is linked to a reduced sensitivity to exogenous FSH. This is demonstrated by a higher total dose of gonadotropins used during ovarian stimulation for IVF $[5,6,9,11]$, a lower peak of estradiol levels on the day of hCG administration $[6,19]$, a lower number of retrieved oocytes $[11,15]$, and a higher incidence in hypo-responders [20]. Nevertheless, in one study, the patients who were homozygous for the $\mathrm{G} / \mathrm{G}$ variant showed a higher number of mature oocytes than the patients homozygous for the $\mathrm{A} / \mathrm{A}$ variant [10].

The discrepancy among the different studies may be due to the different ethnicity of the populations considered and/or to the absence of a strict analysis of confusing clinical variables. Furthermore, the effect of c.-29 G $>$ A polymorphism in almost all of these studies was not considered. On the basis of our results, also considering the fact that the $\mathrm{G} / \mathrm{G}$ variant of c.-29 $\mathrm{G}>\mathrm{A}$ was associated to a lower poor response rate with a strong significance $(p=0.01)$, this polymorphism is of a higher value than c.2039 $\mathrm{A}>\mathrm{G}$ in predicting ovarian response.

In our study, no correlation between the two polymorphisms and basal FSH was found. This observation contradicts various studies conducted on c.2039 A $>\mathrm{G}$ [5-11] but is similar to others [12-17]. In the studies focusing on c.-29 G>A polymorphism, no correlation was found with basal FSH [4, 28-30]; this was in line with our observation.

In the present study, the $\mathrm{A} / \mathrm{A}$ variant for c.-29 $\mathrm{G}>\mathrm{A}$ was associated with a lower AFC than that for the wild type $(p<0.05)$; ours is the first demonstration of this correlation.

As a secondary result, we found that clinical variables (such as BMI, AFC, and starting rhFSH dose) had an influence on the number of oocytes retrieved. Specifically, AFC proved to be positively associated with the outcome, whereas BMI and starting dose were negatively associated.

A large body of evidence, summarized in a recent systematic review [34], indicates that $\mathrm{AFC}$ and $\mathrm{AMH}$ may be considered the best markers of ovarian reserve; they play a similar role in predicting oocyte yield, both being associated with the cohort of primordial follicles. In our study, we found the association with the number of oocytes retrieved only for AFC and not for AMH. The reasons for this finding may be identified in the improved standardization of AFC performed in our clinic: SonoAVC was used, a tool which improves the reliability of results and reduces the variability intra- and interobserver, thereby providing a method of quality control [35]. Furthermore, in order to eliminate any inter-observer potential bias, the AFC determinations were carried out by the same physician. On the other hand, the reduced performance of AMH in predicting oocyte yield, compared with AFC, could be due to the fact that the determinations were not conducted by the same laboratory with a possible lack of standardization in the results regarding major technical limitations (abnormal batches of calibrators, storage of blood samples at room temperature, poor operator reproducibility). This represents a well-recognized problem, as recently indicated by Nelson [36]. The new, fully automated AMH assays, which allow for more efficient sample processing, should help to further reduce, in the near future, the high variability described above.

Regarding the effect of BMI on the number of retrieved oocytes, its negative association with oocyte retrieval has already been demonstrated in literature [37, 38]. Increasing the starting dose of gonadotropins is ineffective for preventing a negative ovarian response. This was proven by the negative association of the starting rhFSH dose with the number of oocytes collected, being the highest doses used in patients with a poor prognosis. Our data is consistent with those of two randomized trials [39, 40].

The present trial has some limitations, basically linked to the low frequencies of some genetic variants. Indeed, as previously reported in the "Results" section, the lack of statistically significant differences in response rate between some groups may simply reflect an inadequate sample size needed to provide the necessary statistical power.

In this study, the long-standard GnRH agonist protocol was utilized. The decision for using this protocol was because different authors proposed the GnRH agonist long protocol as the most useful in expected normal responders [34, 36, $41,42]$, which represent the great majority of our sample. As regards the management of expected poor responders, there are very few in this paper, even though there is a trend toward the use of GnRH antagonists [34, 41, 42]; the results of a recent paper [43] and those of two meta-analyses [44, 45] do not indicate the superiority of one protocol of pituitary suppression over another. Moreover, in clinical practice, despite the growing use of the GnRH antagonist, the long standard protocol is still applied in a very high percentage of cycles. Furthermore, we believe that studies which analyze polymorphisms could be carried out irrespective of the pituitary suppression protocol used. 
In conclusion, this paper indicates that the patients with the A/G-G/G genetic variant retrieve a higher number of oocytes. If confirmed in a larger number of patients, this allelic variant, identified as an independent variable, could be considered as a new genetic biomarker, which could increase the efficiency of prediction models for ovarian stimulation. The authors of this paper contend that the analysis of the combination of c.2039 $\mathrm{A}>\mathrm{G}$ and c.-29 $\mathrm{G}>\mathrm{A}$ should be introduced into routine clinical practice, alongside the classic markers of ovarian reserve (female age, AFC, AMH, basal FSH); this would help in providing specific counseling and choosing the best stimulation protocol.

\section{Compliance with ethical standards}

Conflict of interest The authors declare that they have no conflict of interest.

Funding This research did not receive any specific grant from any funding agency in the public, commercial, or not-for-profit sector; the funds were provided directly by Centro Andros S.r.l., Palermo, Italy.

\section{References}

1. Sunkara SK, Rittenberg V, Raine-Ferring N, Bhattacharya S, Zamora J, Coomarasamy A. Association between the number of eggs and live birth in IVF treatment: an analysis of 400.135 treatment cycles. Hum Reprod. 2011;26:1768-74.

2. Genro VK, Grynberg M, Scheffer JB, Roux I, Frydman R, Fanchin R. Serum anti-Müllerian hormone levels are negatively related to Follicular Output RaTe (FORT) in norm-cycling women undergoing controlled ovarian hyperstimulation. Hum Reprod. 2011;26: $671-7$.

3. Aittomaki K, Pakarinen P, Sistonen P, Tapanainen J, Gromoll J. Mutation in the follicle-stimulating hormone receptor gene causes hereditary hypergonadotropic ovarian failure. Cell. 1995;82:95968.

4. Wunsch A, Ahda Y, Banaz-Yasar F, Sonntag B, Nieschlag E, Simoni M, et al. Single-nucleotide polymorphisms in the promoter region influence the expression of the human follicle-stimulating hormone receptor. Fertil Steril. 2005;84:446-53.

5. Perez-Mayorga M, Gromoll J, Behere HM, Gassner C, Nieschlag E, Simoni M. Ovarian response to follicle-stimulating hormone (FSH) stimulation depends on the FSH receptor genotype. J Clin Endocrinol Metab. 2000;85:3365-9.

6. Sudo S, Kudo M, Wada S, Sato O, Hsueh AJ, Fujimoto S. Genetic and functional analyses of polymorphisms in the human FSH receptor gene. Mol Hum Reprod. 2002;8:893-9.

7. Jun JK, Yoon JS, Ku S-Y, Choi YM, Hwang KR, Park SY, et al. Follicle-stimulating hormone receptor gene polymorphism and ovarian responses to controlled ovarian hyperstimulation for IVFET. J Hum Genet. 2006;51:665-70.

8. Loutradis D, Patsoula E, Minas V, Koussidis GA, Antsaklis A, Michalas S, et al. FSH receptor gene polymorphisms have a role for different ovarian response to stimulation in patients entering IVF/ICSI-ET programs. J Assist Reprod Genet. 2006;23:177-84.

9. Yao Y, Ma CH, Tang HL, Hu YF. Influence of follicle-stimulating hormone receptor (FSHR) Ser680Asn polymorphism on ovarian function and in-vitro fertilization outcome: a meta-analysis. Mol Genet Metab. 2011;103:388-93.
10. Boudjenah R, Molina-Gomes D, Torre A, Bergere M, Bailly M, Boitrelle F, et al. Genetic polymorphisms influence the ovarian response to $\mathrm{rFSH}$ stimulation in patients undergoing in vitro fertilization programs with ICSI. PLoS One. 2012;7, e38700.

11. Huang X, Li L, Hong L, Zhou W, Shi H, Zhang H, et al. The Ser680Asn polymorphism in the follicle-stimulating hormone receptor gene is associated with the ovarian response in controlled ovarian hyperstimulation. Clin Endocrinol. 2015;82:577-83.

12. Falconer H, Andersson E, Aanesen A, Fried G. Follicle-stimulating hormone receptor polymorphisms in a population of infertile women. Acta Obstet Gynecol Scand. 2005;84:806-11.

13. Klinkert ER, te Velde ER, Weima S, van Zandvoort PM, Hanssen $\mathrm{RG}$, Nilsson PR, et al. FSH receptor genotype is associated with pregnancy but not with ovarian response in IVF. Reprod Biomed Online. 2006;13:687-95.

14. Achrekar SK, Modi DN, Desai SK, Mangoli VS, Mangoli RV, Mahale SD. Follicle-stimulating hormone receptor polymorphism ( $\operatorname{Thr}(307) A l a)$ is associated with variable ovarian response and ovarian hyperstimulation syndrome in Indian women. Fertil Steril. 2008;91:432-9.

15. Sheikhha MH, Eftekhar M, Kalantar SM. Investigating the association between polymorphism of follicle-stimulating hormone receptor gene and ovarian response in controlled ovarian hyperstimulation. J Hum Reprod Sci. 2011;4:86-90.

16. Mohiyiddeen L, Newman WG, McBurney H, Mulugeta B, Roberts SA, Nardo LG. Follicle-stimulating hormone receptor gene polymorphisms are not associated with ovarian reserve markers. Fertil Steril. 2012;97:677-81.

17. La Marca A, Papaleo E, Alviggi C, Ruvolo G, De Placido G, Candiani $\mathrm{M}$, et al. The combination of genetic variants of the FSHB and FSHR genes affects serum FSH in women of reproductive age. Hum Reprod. 2013;28:1369-74.

18. Mohiyiddeen L, Nardo LG. Single-nucleotide polymorphisms in the FSH receptor gene and ovarian performance: future role in IVF. Hum Fertil. 2010;13:72-8.

19. Behre HM, Greb RR, Mempel A, Sonntag B, Kiesel L, Kaltwasser $\mathrm{P}$, et al. Significance of a common single nucleotide polymorphism in exon 10 of the follicle-stimulating hormone (FSH) receptor gene for the ovarian response to FSH: a pharmacogenetic approach to controlled ovarian hyperstimulation. Pharmacogenet Genomics. 2005; 15:451-6.

20. Alviggi C, Conforti A, Caprio F, Gizzo S, Noventa M, Strina I, et al. In estimated good prognosis patients could unexpected "hyporesponse" to controlled ovarian stimulation be related to genetic polymorphisms of FSH receptor? Reprod Sci. 2016;23:11038.

21. Daelemans C, Smits G, de Maertelaer V, Costagliola S, Englert Y, Vassart G, et al. Prediction of severity of symptoms in iatrogenic ovarian hyperstimulation syndrome by follicle-stimulating hormone receptor Ser680Asn polymorphism. J Clin Endocrinol Metab. 2004;89:6310-5.

22. Mohiyiddeen L, Newman WG, Cerra C, McBurney H, Mulugeta B, Roberts SA, et al. A common Asn680Ser polymorphism in the follicle-stimulating hormone receptor gene is not associated with ovarian response to gonadotropin stimulation in patients undergoing in vitro fertilization. Fertil Steril. 2013;99:149-55.

23. Genro VK, Matte U, De Conto E, Cunha-Filho JS, Fanchin R. Frequent polymorphisms of FSH receptor do not influence antral follicle responsiveness to follicle-stimulating hormone administration as assessed by the Follicular Output RaTe (FORT). J Assist Reprod Genet. 2012;29:657-63.

24. Lindgren I, Bååth M, Uvebrant K, Dejmek A, Kjaer L, Henic E, et al. Combined assessment of polymorphisms in the LHCGR and FSHR genes predict chance of pregnancy after in vitro fertilization. Hum Reprod. 2016;31:672-83. 
25. Tang H, Yan Y, Wang T, Zhang T, Shi W, Fan R, et al. Effect of follicle-stimulating hormone receptor Asn680Ser polymorphism on the outcomes of controlled ovarian hyperstimulation: an updated meta-analysis of 16 cohort studies. J Assist Reprod Genet. 2015;32:1801-10.

26. Moròn FJ, Ruiz A. Pharmacogenetics of controlled ovarian hyperstimulation: time to corroborate the clinical utility of FSH receptor genetic markers. Pharmacogenomics. 2010;11:1613-8.

27. La Marca A, Sighinolfi G, Argento C, Grisendi V, Casarini L, Volpe $\mathrm{A}$, et al. Polymorphisms in gonadotropin and gonadotropin receptor genes as markers of ovarian reserve and response in in vitro fertilization. Fertil Steril. 2013;99:970-8.

28. Tohlob D, Abo Hashem E, Ghareeb N, Ghanem M, Elfarahaty R, Byers $\mathrm{H}$, et al. Association of a promoter polymorphism in FSHR with ovarian reserve and response to ovarian stimulation in women undergoing assisted reproductive treatment. Reprod Biomed Online. 2016;33:391-7.

29. Achrekar SK, Modi DN, Desai SK, Mangoli VS, Mangoli RV, Mahale SD. Poor ovarian response to gonadotropin stimulation is associated with FSH receptor polymorphism. Reprod Biomed Online. 2009;18:509-15.

30. Desai SS, Achrekar SK, Pathak BR, Desai SK, Mangoli VS, Mangoli RV, et al. Follicle-stimulating hormone receptor polymorphism (G-29A) is associated with altered level of receptor expression in Granulosa cells. J Clin Endocrinol Metab. 2011;96:280512.

31. Desai SS, Achrekar SK, Paranjape SR, Desai SK, Mangoli VS, Mahale SD. Association of allelic combinations of FSHR gene polymorphisms with ovarian response. Reprod Biomed Online. 2013;27:400-6.

32. American Society for Reproductive Medicine. Revised American Society for Reproductive Medicine classification of endometriosis: 1996. Fertil Steril. 1997;67:817-21.

33. Volpes A, Sammartano F, Coffaro F, Mistretta V, Scaglione P, Allegra A. Number of good quality embryos on day 3 is predictive for both pregnancy and implantation rates in in vitro fertilization/ intracytoplasmic sperm injection cycles. Fertil Steril. 2004;82: 1330-6.

34. La Marca A, Sunkara SK. Individualization of controlled ovarian stimulation in IVF using ovarian reserve markers: from theory to practice. Hum Reprod Update. 2014;20:124-40.
35. Deb S, Batcha M, Campbell BK, Jayaprakasan K, Clewes JS, Hopkisson JF, et al. The predictive value of the automated quantification of the number and size of small antral follicles in women undergoing ART. Hum Reprod. 2009;24:2124-32.

36. Nelson S. Biomarkers of ovarian stimulation: current and future applications. Fertil Steril. 2013;99:963-9.

37. Pinborg A, Gaarsley C, Hougaard CO, Nyboe Andersen A, Andersen PK, Boivin J, et al. Influence of female bodyweight on IVF outcome: a longitudinal multicentre cohort study of 487 infertile couples. Reprod Biomed Online. 2011;23:490-9.

38. Rittenberg V, Seshadri S, Sunkara SK, Sobaleva S, Oteng-Ntim E, El-Toukhy T. Effect of body mass index on IVF treatment outcome: an updated systematic review and meta-analysis. Reprod Biomed Online. 2011;23:421-39.

39. Klinkert ER, Broekmans FJ, Looman CW, Habbema JD, teVelde ER. Expected poor responders on the basis of an antral follicle count do not benefit from a higher starting dose of gonadotropins in IVF treatment: a randomized controlled trial. Hum Reprod. 2005;20:611-5.

40. Berkkanoglu M, Ozgur $\mathrm{K}$. What is the optimum maximal gonadotropin dosage used in microdose flare-up cycles in poor responders? Fertil Steril. 2010;94:662-5.

41. Nelson SM, Yates RW, Lyall H, Jamieson M, Traynor I, Gaudoin $\mathrm{M}$, et al. Anti-Müllerian hormone-based approach to controlled ovarian stimulation for assisted conception. Hum Reprod. 2009;24:867-75.

42. Yates AP, Rustamov O, Roberts SA, Lim HY, Pemberton PW, Smith A, et al. Anti-Mullerian hormone-tailored stimulation protocols improve outcomes whilst reducing adverse effects and costs of IVF. Hum Reprod. 2011;26:2353-62.

43. Stimpfel M, Vrtačnik-Bokal E, Pozlep B, Kmecl J, Virant-Klun I. Gonadotropin-releasing hormone agonist protocol of controlled ovarian hyperstimulation as an efficient treatment in Bolognadefined poor ovarian responders. Syst Biol Reprod Med. 2016;62: 290-6.

44. Pandian Z, McTavish AR, Aucott L, Hamilton MP, Bhattacharya S. Interventions for 'poor responders' to controlled ovarian hyper stimulation $(\mathrm{COH})$ in in-vitro fertilisation (IVF). Cochrane Database Syst Rev. 2010;1, CD004379.

45. $\mathrm{Pu} \mathrm{D}, \mathrm{Wu}$ J, Liu J. Comparisons of GnRH antagonist versus GnRH agonist protocol in poor ovarian responders undergoing IVF. Hum Reprod. 2011;26:2742-9. 